\title{
Teenage pregnancies/HIV prevention - doctors help fill official hiatus
}

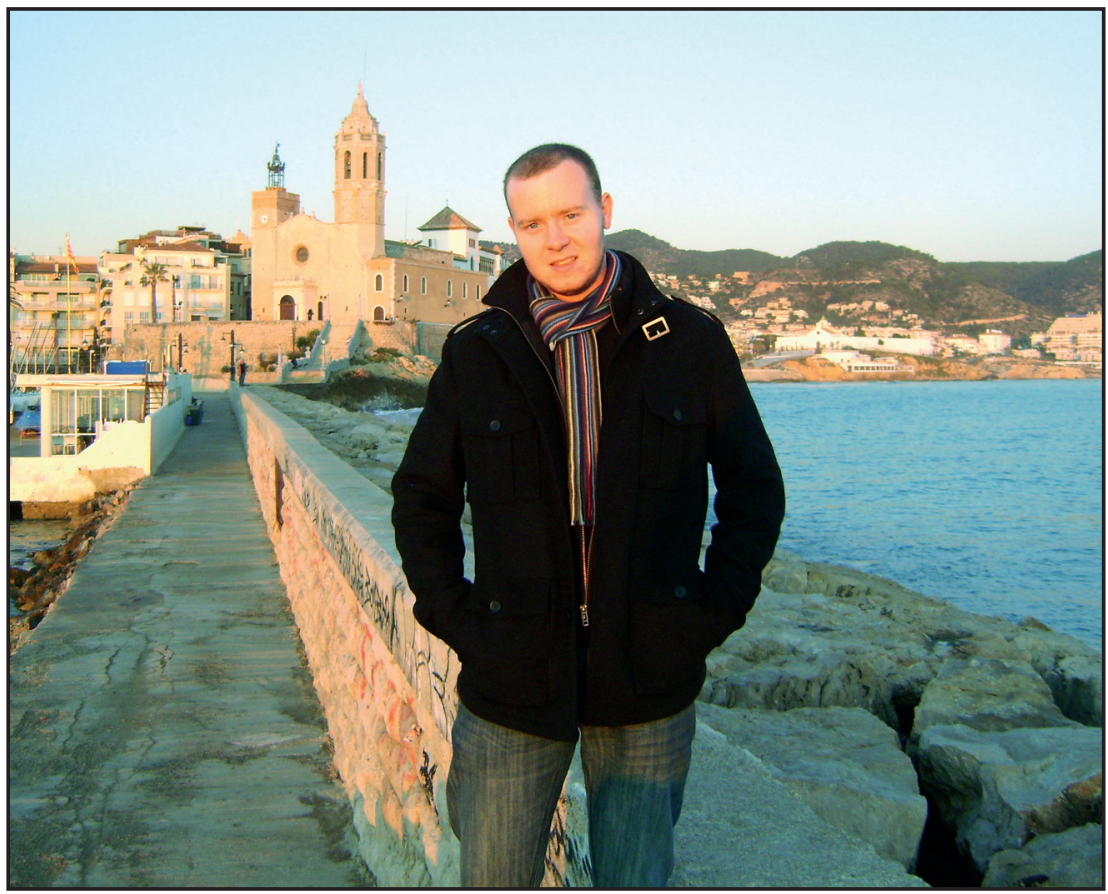

Gauteng-based surgical medical officer, Dr Kalli Spencer.

A young former Chris Hani/Baragwanath Hospital intern, troubled by a high patient load of pregnant teenagers, many with complications, has begun conducting 'shock therapy' school workshops across Johannesburg, aimed at reducing longterm emotional and physical harm.

\section{Those that stuck in his memory were the 16-year-olds with} previous C-sections, a 17-yearold whose baby died in the ICU (congenital heart deformity) and a 22-year-old with an ectopic pregnancy who died in his arms (with boyfriend in tow).

Dr Kalli Spencer, 27, now a surgical medical officer at the Charlotte Maxeke Johannesburg Academic Hospital, teamed up with an NGO and other young colleagues rotating through the surgical and obstetrics and gynaecology departments at his hospital to heighten prevention awareness. In their spare time and working with the 'Just-1Teenager' NGO and the local education department, they've helped fill a pregnancy awareness gap in successful HIV behaviourchange campaigns (Love Life, Soul City and Khomanani) - and address the social stigma which the often patient-unfriendly public health system aggravates. ${ }^{1}$ Spencer, the Junior Doctors Association of South Africa's (JUDASA's), project co-ordinator and marketing director, says a quarter of all the patients he treated at the obstetrics and gynaecology unit in Chris Hani/Bara were pregnant teenagers.

Those that stuck in his memory were the 16-year-olds with previous C-sections, a 17-year-old whose baby died in the ICU (congenital heart deformity) and a 22-yearold with an ectopic pregnancy who died in his arms (with boyfriend in tow), before they could get her to Chris Hani/Bara. 'They're just not emotionally and physically mature enough to deal with this ... and that's not to mention the numerous cases of kwashiorkor babies (mothers unable to afford to feed or ignorant of appropriate nutrition), and those preggie because of sugar daddies, he added.

\section{'Connecting the dots' - junior doctor}

The initial vehicle for Spencer's response was the national health department's Pregnancy Awareness Week in February
2010. 'I think as doctors we don't make enough time to reflect on what we can do to change things. If it wasn't for that pregnancy awareness campaign I don't think I would have connected the dots. Then at JUDASA, the subject of what we could do came up - so I took a team to the Rand Girls High School in Parktown. By the time of going to press Spencer's current team had completed half-day workshops at nearly a dozen schools, including several in Pimville, Soweto. The interactive workshop (tailored to primary and secondary schools) includes a PowerPoint presentation on normal sexual development (and what can go wrong) before moving onto the worst complications of pregnancy, sexually transmitted infections (and long-term complications), HIV complications and abortion, but focusing mainly on abstinence and touching on contraception if they were to consider it'. 'Contraception is excluded from the workshop at Catholic schools where pupils' questions have centred on "what is a climax or orgasm?" and "what is Viagra?" ... the parents don't realise what their little angels actually know. You can look at the faces in the audience and see who knows what's going on and the innocent faces registering shock - they're the ones you make the impact on, he says. Asked to elaborate on the 'shock therapy' presentation, Spencer said it began with ectopic pregnancies, moving on to abortion (depicting the actual manual aspiration device at work), a picture of a fetus with a woman pointing a gun at it, plus other slides on congenital deformities, sexually transmitted infections (STIs), ulcers, discharges and a detailed depiction of 'how expensive babies actually are. $\mathrm{He}$ told teenagers that the depictions were 'rare complications ... but I ask them, "how do you know you are not the one person they happen to?"' Spencer said his campaign was anything but religiously inspired; 'I'm a doer, responding to my experience of what's going on the ground, not some higher political or policy echelon.'

\section{Health Dept endorses schools HIV testing hiatus}

The Department of Basic Education earlier this year discontinued HIV testing at schools (and thus any attendant pregnancy awareness education) - vital to behaviour change before 
'learners' enter a more sexually active, agedifferentiated and far higher HIV prevalence societal pool. Confronted by an influential youth activist organisation, Yezingane, over the lack of psycho-social support, Basic Education Minister Angie Motshekga backed down, placing herself at odds with the HIV/AIDS and Sexually Transmitted Infections Directorate in the health department. After several urgent phone calls and meetings, the two government departments, with input from National Health Minister, Dr Aaron Motsoaledi, agreed to continue the suspension of testing until the implementation of the pre-nationalhealth-insurance-integrated school health programme. This nurse-led programme is intended to be far more co-ordinated, with full consultation of school bodies, NGOs, parents, learners and referral networks prior to inception - but the 6 - 12-month testing hiatus could prove costly in the HIV infection battle.

\section{The Department of Basic} Education earlier this year discontinued HIV testing at schools (and thus any attendant pregnancy awareness education)

- vital to behaviour change

before 'learners' enter a more sexually active, age-differentiated and far higher HIV prevalence societal pool.

Dr Thobile Mbengashe, Chief Director of HIV/AIDS and STIs in the national Department of Health told Izindaba that interventions from awareness bodies like LoveLife, Khomanani and Soul City would continue while the health department still provided free termination of pregnancy services to girls and women in their first trimesters. However, 'protecting and providing something (awareness) that is relevant and topical and not detrimental to the psyches of young people,' was crucial and for this wider consultation was 'essential'. When pressed, he estimated that this would take 'not more than a year, perhaps between 6 and 8 months ... it's hard to say'.

\section{Qualified warning}

Both he and Dr Gustaaf Wolvaardt, $\mathrm{CEO}$ of the Foundation for Professional Development, warned against a 'shock therapy' approach, adding that, while potentially effective, sexuality and sexual health were equally vital components of development. Said Mbengashe, 'You don't want to dramatise or traumatise people and make it into a horrible thing. Any programme should also go through due process (of consultation) - and make sure we're doing no harm.'

Wolvaardt described Spencer and his fellow doctors' initiative as 'absolutely great - a small group of dedicated people can change the world. You just have to see what Pieter Dirk-Uys (the comedian) has done at schools. Obviously these guys are seeing where the gap is in the big focus on preventing HIV/AIDS. In a survey we did in Tshwane, half the kids admitted they were sexually active and only half were cognitively aware that they were practising unsafe sex, he emphasised. However getting the opinion of children and the organisations that represented them, not to mention teacher and parent bodies was necessary. 'Our experience is that this school thing is a buzz saw. You stick your hand in and it'll get cut off. South Africa is a very conservative society, across cultures. These well-intentioned young doctors need to consult experts in the field before somebody goes hysterical and a good programme gets into trouble, he added.

\section{Teenage pregnancy data}

Surveys of mainstream (government and private) schools show there are more than 45000 teenage pregnancies in any one year. A LoveLife survey conducted by the Reproductive Health Research Unit in 2003 indicated that the rate of teenage pregnancies in South Africa had not diminished despite wide-ranging initiatives to improve reproductive health counselling and related services. A 1998 South African Demographic and Health Survey revealed that about $2.4 \%$ of the adolescent girls canvassed had fallen pregnant by the age of 15 , with $35 \%$ of the sample reporting a pregnancy by the age of 19 . The Department of Health's figures (1990 survey) estimated the teenage pregnancy rate to be $330 / 1000$ under the age of 19 (USA rate 52/1 000). Among blacks, the proportion of births resulting from teenage pregnancies was reported to have risen from $12.4 \%$ in 1984 to $15.5 \%$ in 1991 . One probe demonstrates that young women, the fathers $(18-22$ years old), and their parents are 'locked into a silence of fear and shame, preventing them from providing mutual support and from accessing available services'. Sexual and reproductive health and educational services for young people were also subject to 'moral paralysis, rendering them equivocal in their dealings with teenage mothers and fathers, and leading young parents to experience these services as distant and inaccessible, it added. $^{2}$

In a survey we did in Tshwane, half the kids admitted they were sexually active and only half were cognitively aware that they were practising unsafe sex,' he emphasised.

Spencer's spark and passion also led to him starting a circumcision clinic at the Helen Joseph Hospital during his community service year - fulfilling a long-standing wish of many busy full-time colleagues. $\mathrm{He}$ used his JUDASA portfolio experience to market and promote circumcision at schools, colleges, technikons and various vehicle-licensing departments. Supported by the Centre for HIV/AIDS and Prevention Studies (CHAPS), a private NGO funded by the World Health Organization, and the President's Emergency Plan for AIDS Relief (PEPFAR), Spencer has personally done 1000 circumcisions, working at various CHAPS clinics across Soweto. Eighteen months down the line, the Helen Joseph Clinic, linked to the HIV-management NGO

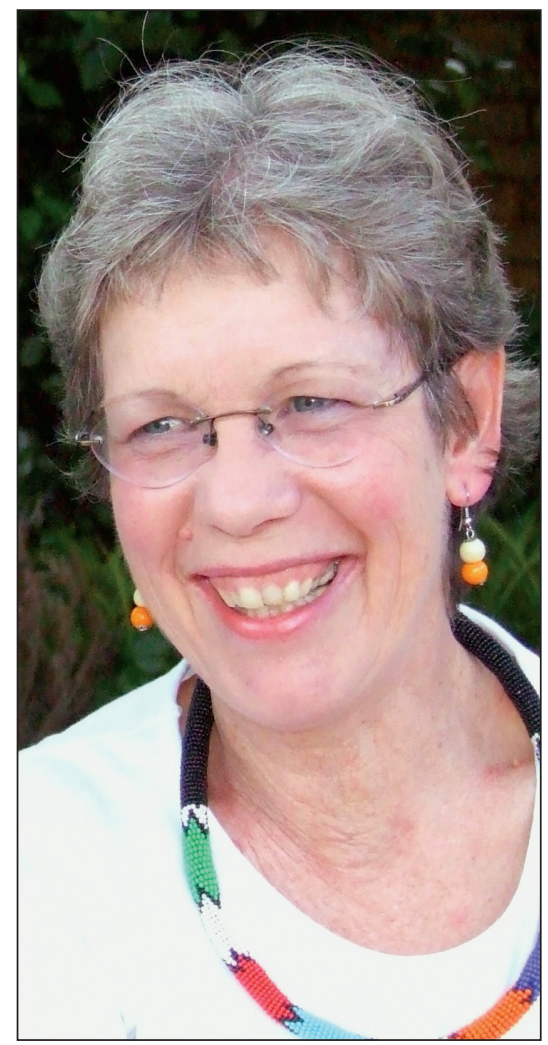

Midwife and 'Just-1-Teenager' founder, Sister Burgi Ireland. 
'Right to Care,' has a comprehensive service that conducts rapid HIV tests (circumcision done if CD4 count is greater than 200 and antiretroviral therapy added from CD4 count of 350 upwards, plus TB prevention treatment - INH for post-contact).

\section{'Just-1-Teenager' - how it began}

Spencer told Izindaba that his long-term goal is to set up a public sector men's health clinic where he could use a captive audience to address issues like intimate partner violence and sexual health. The 'Just-1-Teenager' NGO he worked with was established over a decade ago by qualified midwife, Sister Burgie Ireland, after her 14-year old-daughter (now 31) fell pregnant and chose to have her child while completing her education. Ireland's programme gets teenagers to understand and appreciate the benefits of delaying sexual debut, addresses abusive behaviour (many pupils come from dysfunctional homes where rape, violence, and alcohol and drug abuse are a daily part of their lives) and encourages open discussion. 'Teachers stay (discreetly in the background) during presentations and parents are invited to a parents' evening beforehand where we encourage them to openly discuss sexuality with their kids. We also prepare a full report for the principal and life orientation teacher (which includes feedback from confidential questionnaires)', she explained. Young, dynamic and motivated doctors 'telling kids not to let it happen to them' were an invaluable resource, she added.

\section{Protective effect of knowledge}

A proud Ireland told Izindaba that her granddaughter, now 16, recently argued so effectively, openly and knowledgably in a school debate on abortion that she was pulled from the anti-abortion debating side and put on the judging panel. Besides talking about the lack of pre- and post-abortion counselling and the misuse of abortion as a family planning tool, her trump card was simply to ask, 'What if my mother had aborted me?' she said. She said questionnaires completed by children her NGO spoke to at Johannesburg schools revealed that $70 \%$ actually wanted HIV testing at schools, not to mention pregnancy information.

\section{Chris Bateman}

chrisb@hmpg.co.za 1. Teenage pregnancy is South Africa -with a specific focus
on school-going learners http://www.info.gov.za/view/
DownloadFileAction?id=122470.
2. Richter LM, Norris SA, Ginsburg C. The silent truth of teenage
pregnancies - Birth to Twenty cohort's next generation. S Afr Med J 2006;96(2):122.

S Afr Med J 2012;102(8):643-645

DOI:10.7196/SAMJ.6081 